\title{
Violência contra professores de Educação Física no ensino público do Estado do Paraná
}

\author{
Gustavo Levandoski ${ }^{1}$ \\ Fabiano Ogg 2 \\ Fernando Luiz Cardoso ${ }^{3}$ \\ ${ }^{1}$ Programa de Doutoramento em Educação Física da Universidade Federal do Paraná \\ UFPR, Curitiba, PR, Brasil \\ 2 Secretaria Estadual de Educação do Paraná- SEED/PR, Brasil \\ ${ }^{3}$ Centro de Educação Física, Fisioterapia e Desportos da UDESC, Florianópolis, SC, \\ Brasil
}

\begin{abstract}
Resumo: O objetivo foi verificar a violência na relação professor-aluno, sofrida por professores de educação física que atuam no ensino fundamental e médio na rede pública de ensino. Participaram deste estudo 102 professores que atuam em 14 cidades do estado do Paraná. Utilizou-se um questionário criado pelos autores com consistência interna de $\alpha=0,902$ (Alpha de Crombach). Os procedimentos estatísticos foram realizados pelo programa SPSS versão $14.0 \mathrm{com}$ nível de significância de $p<0,05$. Constatou-se que $87,3 \%$ dos professores já vivenciaram ou vivem algum episódio referente à atos de violência no ambiente escolar e $73,5 \%$ recebem insultos verbais frequentemente. Os professores da região noroeste do estado, estão mais expostos a situações de agressão pelos alunos em relação aos professores da região central. Esta mesma relação aconteceu com os professores solteiros comparados aos professores casados. Destacamos que os professores que ministram aula em apenas um estabelecimento de ensino sentem-se mais seguros em seu local de trabalho e que os professores do sexo feminino solicitam mais a ajuda para solucionar os conflitos no local de trabalho. Considera-se que a violência contra os docentes nesta relação professor-aluno encontra-se em um nível preocupante.
\end{abstract}

Palavras-chave: Violência escolar. Professor de Educação Física. Relação professor-aluno.

\section{Aggression towards Physical Education teachers in public schools in the state of Paraná}

\begin{abstract}
The objective of this work was to investigate aggression in the teacher-student relationship, experienced by teachers of physical education employed in primary and secondary schools in the public sector. The study involved 102 teachers working in 14 towns in the state of Paraná. A questionnaire developed by the authors was used, with an internal consistency of $\alpha=0.902$ (Crombach's Alpha). Statistical analysis was carried out using the SPSS program version 14.0 with a level of significance of $p<0.05$. It was found that $87.3 \%$ of the teachers had witnessed or experienced an episode involving acts of aggression in the school environment and $73.5 \%$ frequently received verbal insults. Teachers in the northwest region of the state are more exposed to situations of aggression from students compared to teachers from the central region. This relationship was the same among teachers who were single and those who were married. It was notable that teachers who gave classes in only one educational establishment felt safer in their workplace and that female teachers were more likely to seek help to resolve conflicts in the workplace. Aggression towards teaching staff in the teacher-student relationship is concluded to be at a worrying level.
\end{abstract}

Key words: School aggression. Physical Education teacher. Teacher-student relationship.

\section{Introdução}

Cotidianamente, os profissionais da educação estão convivendo com situações de violência, passando a ser reféns de ações que também afligem a maioria da população mundial (WORLD HEALTH ORGANIZATION WHO, 2002; FERNANDEZ, AGUADO e CANTERO, 2006). A grande preocupação, é que esses atos são praticados muitas vezes por adolescentes e jovens que ainda não completaram a maioridade civil, e que por sua vez frequentam ainda as instituições de ensino básico (ABRAMOVAY, 2006).

Foi somente na década de 1980 que a temática da violência emergiu como um problema de saúde pública no Brasil (SPOSITO, 2001). A partir dos debates sobre estas questões, Deslandes, (1994) descreve que é desconhecida a frequência exata de casos como abusos, maus tratos nesta década, pois existiam poucos os serviços para identificação. De acordo com pesquisas da Organização das Nações Unidas para Educação, Ciência e Cultura Unesco (2003), 
existem evidências indicando que o volume das ocorrências sobre a violência na escola é preocupante, tanto na percepção dos alunos, quanto entre professores e membros da equipe pedagógica das escolas. Sabe-se que em média, $8 \%$ dos alunos e $7 \%$ dos professores já foram vitimas de algum tipo de violência sexual dentro da escola. Outra hipótese é que algumas "brincadeiras", como comentários maliciosos envolvendo a sexualidade de alunos e professores, possam acontecer.

Segundo Minayo, (1994) a violência é um dos eternos problemas da teoria social, não se conhece nenhuma sociedade onde a violência não tenha estado presente. Para Lopes Neto, (2005) o termo violência escolar diz respeito a todos os comportamentos agressivos e antisociais, incluindo os conflitos interpessoais, danos ao patrimônio e atos criminosos. Muitas dessas situações dependem de fatores externos, cujas intervenções podem estar além da competência e capacidade das entidades de ensino e de seus funcionários. Porém percebe-se que não apenas os alunos, mas também, o corpo docente das instituições de ensino básico, estão sujeitos a situações de violência no ambiente escolar.

Apesar de a violência física ser a mais evidente, existe outros tipos tais como a psicológica (PEREIRA, 2002; LEVANDOSKI, 2009) e social (MINAYO, 1994) que são mais frequentes no cotidiano dos professores. Esta violência é marcada pela utilização de termos específicos na visão dos alunos, como apelidos depreciativos que atingem a imagem dos professores.

De acordo com Ricci (1999) quando discute sobre as novas perspectivas educacionais, as mudanças na relação entre professores e alunos não são recentes. Em 1979 nos Estados Unidos a impunidade crescente entre os alunos atingia 5\% do total de professores do ensino público. $O$ fato, é que muitos professores são intimidados ou sofrem ameaças (WORLD HEALTH ORGANIZATION, 2002), são agredidos, de forma física e moral (FERNANDEZ, AGUADO e CANTERO, 2006), tem seus pertences furtados ou danificados (ABRAMOVAY, 2005a) e em alguns casos podem sofrer com assedio sexual (ABRAMOVAY; RUA, 2002).

Para Correia (2008) a violência exacerbada, também é um fator extrínseco que dificulta na atuação profissional em educação física, isto porque com o passar dos anos a figura de autoridade e referência que figurava pelos docentes foi perdendo o respeito na visão dos alunos. Muitas vezes os professores preferem tolerar as situações de violências sabendo que por vezes podem ser interpretados de maneira errada por diretores e equipe pedagógica da escola, gerando assim situações de tensão, estresse, insatisfação com a profissão. Contudo segundo Abramovay (2006) a violência no meio escolar contribui para uma diminuição da qualidade do ensino, acarretando em prejuízos aos próprios alunos.

$\mathrm{Na}$ Espanha, os tipos de violência mais registrados em educadores, e que afetam a relação entre alunos e professores são a violência verbal, física, insultos, ameaças e brigas ocasionais (FERNANDEZ, AGUADO e CANTERO, 2006). Para Tokuyochi et. al. (2008) realizando um estudo com 2700 professores de educação física da rede estadual de São Paulo buscou retratar o perfil das condições de trabalho (experiência, carga horária semanal, rotatividade de instituição, problemas com materiais didáticos e infra-estrutura) na atividade profissional, constatou que na percepção dos professores 95,9\% já presenciarem comportamentos considerados violentos entre alunos durante as aulas.

Segundo Gasparini, Barreto e Assunção (2006) existe a necessidade de avançar os estudos sobre os transtornos relativos à saúde no trabalho de docentes. Recentemente as pesquisas envolvendo os professores de forma geral, retratam sobre situações difíceis no inicio da carreira de docente (BLAYA; BAUDRIT, 2005) os professores diante a violência entre os alunos (FERNANDEZ, AGUADO e CANTERO, 2006; DORREY, 2005), a contextualização do conceito de violência entre os professores (RISTUM; BASTOS, 2004) consequências da violência escolar para equipe pedagógica (ABRAMOVAY, 2005b) e a formação do professor em face da violência nas escolas (GOMES; PEREIRA 2009). Em relação aos docentes da disciplina de Educação Física que atuam nas escolas da rede pública, percebe-se a necessidade de verificar a incidência dos atos de violência na relação professor-aluno em seu ambiente de trabalho?

\section{Método}

O presente estudo trata-se de uma pesquisa descritiva- exploratória não probabilística, com 
tipo amostral intencional e por acessibilidade. O objetivo é verificar à violência na relação professor-aluno, sofrida por professores de educação física, que atuam no ensino fundamental e médio da rede pública do estado do Paraná.

\section{Procedimentos}

$O$ instrumento de pesquisa utilizado foi construído a partir dos estudos de (LEVANDOSKI, 2009; TROMBETTA, 2005; SANTINI; NETO, 2005; GLINA; GARDIN, 2005; ABRAMOVAY, 2005a; SPOSITO, 1998; SEBASTIÃO, ALVES e CAMPOS, 2003; ABRAMOVAY E RUA, 2002; DEBARBIEUX 2002) com a preocupação de verificar como é a relação entre professor e aluno no ambiente escolar diante os possíveis episódios de violência nesta relação. Buscou-se com o questionário averiguar: (1) Você já vivenciou ou vive algum episódio referente à "atos de violência" no ambiente escolar? (2) Você já recebeu ou recebe insultos verbais de seus alunos? (3) Você já teve seus pertences, furtado ou danificado e desconfia que sejam seus alunos? (4) Você já foi intimidado por algum aluno que portava arma de fogo ou branca? (5) Você já vivenciou ou vive alguma situação de extorsão, tendo que favorecer contra sua vontade alguns de seus alunos à passar de ano ou favorecer seu desempenho? (6) Você teme ou temeu por sua integridade física ao repreender por qualquer motivo algum aluno? (7) Você teve receio de impedir uma situação de conflito entre os alunos por receio de sofrer com represálias por partes dos mesmos em outras oportunidades? (8) Sentiu-se assediado(a) sexualmente por alunos(as) durante exercício da profissão? (9) Existe algum espaço físico na escola onde você sente-se inseguro ou intimidado no momento? (10) Sentiu-se ameaçado como ao ponto de pedir segurança policial para entrar ou sair da escola? (11) Você já tentou pedir ajuda a seus superiores? O questionário apresentou uma consistência interna de $\alpha=0,902$ (Alpha de Crombach) obtido em um estudo piloto não publicado.

\section{Os participantes e critérios de inclusão}

A coleta de dados foi realizada durante os meses de setembro, outubro, novembro e dezembro do ano letivo de 2009. Inicialmente foram convidados a participar do estudo 124 professores, mas ao final do estudo devido aos critérios de inclusão obteve-se um total de 102 professores que atuam em 14 cidades do estado do Paraná. A Figura 1, ilustra o mapa do Paraná bem como em destaque as cidades que correspondem ao local de trabalho dos docentes participantes.

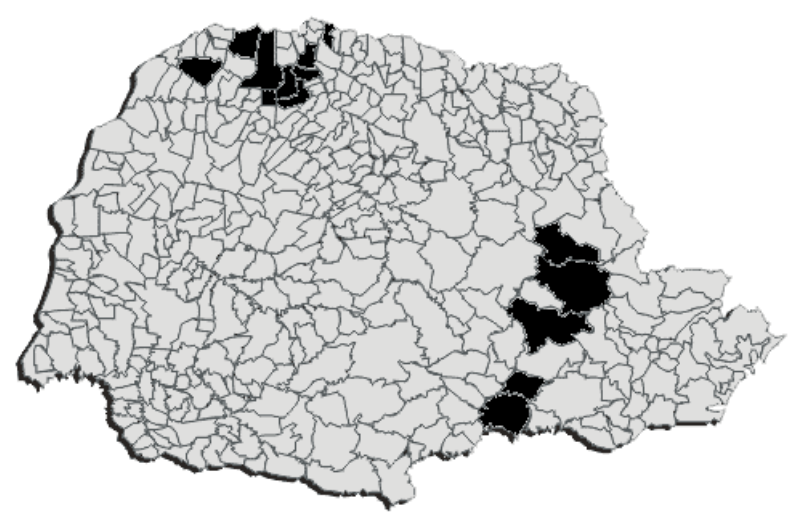

Figura 1. Mapa do Paraná destacando as cidades envolvidas

Para efeito de comparação durante uma etapa da análise estatística chamaremos de "região 1" o grupo composto pelas cidades localizadas no noroeste do estado (Paranavaí, Loanda, Terra Rica, Nova Esperança, Alto Paraná, Tamboara, Itaguagé, Paranacity e Cruzeiro do Sul) contendo um total de 55 professores, sendo 26 do sexo masculino e 29 do sexo feminino; e "região 2" o grupo composto pelas cidades próximas ao centro do estado (Ponta Grossa, Castro, Piraí do Sul, São Mateus do Sul e São João do Triunfo) contendo um total de 47 professores, sendo 25 do sexo masculino e 22 do sexo feminino.

De acordo com os critérios de inclusão os participantes deveriam ser: (1) professores graduados em educação física em pleno exercício profissional, (2) mínimo de dois anos de experiência docente; (3) ministrando aulas no ensino público estadual; (4) carga horária semanal superior à dez horas/aula. Todos foram informados sobre os procedimentos através do Termo de Consentimento Livre e Esclarecido que relata os procedimentos e a intenção da pesquisa, de acordo com as "Diretrizes e Normas Regulamentadoras de Pesquisa Envolvendo Seres Humanos" (196/96), editadas pela Comissão Nacional de Saúde e aprovado pelo Comitê de Ética da Universidade Federal do Paraná.

\section{Tratamento estatístico}

A análise estatística foi através do programa Statistical Package for the Social Science (SPSS 
for Windows) versão 14.0. Na análise dos dados foram utilizadas medidas de tendência central, e aplicação de teste não-paramétrico como Quiquadrado e $U$ de Mann-Whitney. Os procedimentos de análise do presente estudo foram realizados com nível de significância fixado em $\mathrm{p}<0,05$.

\section{Resultados}

\section{Em relação ao número total de docentes}

$\mathrm{Na}$ tabela 1 constam os valores (médios, desvio padrão, mínimos e máximos) em relação à idade e tempo de magistério em anos, a carga horária semanal em horas e o número de escolas de atuação profissional. A fim de indicar o perfil do grupo de professores de educação física avaliados, os valores em percentual correspondem ao estado civil dos docentes.

Tabela 1. Perfil dos participantes

\begin{tabular}{lcccc}
\hline $\mathbf{n = 1 0 2}$ & & Média $\pm \mathbf{d p}$ & Máximo & Mínimo \\
\hline $\begin{array}{l}\text { Idade } \\
\begin{array}{l}\text { Tempo de } \\
\text { magistério }\end{array}\end{array}$ & anos & $(37,52 \pm 8,7)$ & 59 & 23 \\
$\begin{array}{l}\text { Carga horária } \\
\text { semanal }\end{array}$ & horas & $(34,96 \pm 9,1)$ & 60 & 10 \\
$\begin{array}{l}\text { Quantidade } \\
\text { de escolas }\end{array}$ & & $(1,9 \pm 0,8)$ & 5 & 1 \\
& Solteiro & Casado & Divorciado & Viúva \\
Estado civil & $34,8 \%$ & $58,8 \%$ & $5,9 \%$ & $1,0 \%$ \\
\hline
\end{tabular}

Os dados da tabela 2 evidenciam a frequência em percentual das respostas do questionário utilizado para verificar atos de violência na relação professor-aluno no ambiente escolar.

Segundo os professores pesquisados quando questionados se "já vivenciou ou vive algum episódio referente à atos de violência no ambiente escolar", 87,3\% responderam "sim", indicando um percentual bem elevado. Mesmo tratando-se de ações indiretas $76,5 \%$ informaram que a frequência de receber insultos verbais são de $28,4 \%, 12,7 \%, 4,9 \%, 5,9 \%$ e $20,6 \%$ as quais acontecem em (1, 2, 3, 4 e 5) dias semanais respectivamente.

Em relação à questão que avaliou se os professores "já tiveram receio de impedir uma situação de conflito entre os alunos por receio de sofrer com represálias" constatou-se que $41,2 \%$ responderam "sim". Quando perguntados sobre "temer por sua integridade física ao repreender por qualquer motivo algum aluno" $60,4 \%$ afirmaram temer por sua integridade física. Corroborando a estas ações 7,8\% dos professores relataram terem sido ameaçado com arma de fogo ou arma branca por alunos e 6,9\% já viveu ou vive alguma situação de extorsão para favorecer os alunos à passarem de ano.

Perguntamos aos professores se eles desconfiam que seu alunos já furtaram ou danificaram seus pertences, e $27,5 \%$ destes responderam "sim". Deste total $30,8 \%$ teve seu carro danificado, e os $74,5 \%$ tiveram alguns de seus pertences como óculos, celular, dinheiro, livros de registro de classe, material didático danificado ou furtado.

Ao perguntar se já sentiram-se assediado sexualmente por alunos(as) durante o exercício da profissão $30,4 \%$ dos professores afirmaram esta indagação. Em relação à existência de espaço físico, perguntamos se existe um local onde os docentes sentem-se inseguros ou intimidados, e $12,7 \%$ responderam "sim" informando que a própria quadra de esportes (local destinado para as aulas), bem como o portal de entrada são um dos locais inseguros.

Verificou-se que existem situações de violência que são resolvidas somente com o auxílio da direção e coordenação dos estabelecimentos de ensino. Perguntamos então, se os docentes já solicitaram este auxílio e $68,4 \%$ responderam "sim". Deste total $40,8 \%$ não teve o problema solucionado, causando uma situação de desconforto na relação professor-aluno.

De forma geral também indagamos sobre a periodicidade destas situações. Buscou-se conhecer por quanto tempo estas situações de medo geradas durante a atividade laboral acompanharam os professores. Encontramos que $38,8 \%, 20,0 \%, 17,5 \%$ e $23,8 \%$ vivenciaram estas ações num período de "um dia", "uma semana", "um mês" e "todo o período que trabalhou na escola" respectivamente.

Em relação a qual período do dia em que estas ações de violência foram vivenciadas as respostas foram as seguintes: $29,5 \%$ trabalham no período matutino, $24,4 \%$ trabalham no período vespertino, $30,8 \%$ trabalham no período noturno e 15,4 trabalham em mais de um período.

\section{Em relação à idade dos participantes}

Para realização desta análise, os participantes foram divididos em quatro grupos distribuídos por frequência de classe: os professores com idades entre 23-32 anos, totalizando 37 professores; 3342 anos, totalizando 36 professores; 43-52 anos, 
totalizando 21 professores; 53-62 anos, totalizando 8 professores. Buscou-se verificar a existência de associação entre as respostas do questionário em relação a idades dos docentes. Através do teste do Qui-quadrado adotando um $p<0,05$ não foram encontradas estatisticamente diferenças significativas, constatando assim não haver associação entre as questões relacionadas à violência na relação entre professores e alunos do ponto de vista da idade dos participantes.

Tabela 2. Frequência das respostas sobre os itens do questionário de todos os docentes

\begin{tabular}{|c|c|c|}
\hline Itens do questionário & Não & Sim \\
\hline $\begin{array}{l}\text { Q1. Você já vivenciou ou vive algum episódio referente à "atos de violência" no } \\
\text { ambiente escolar? }\end{array}$ & $12,7 \%$ & $87,3 \%$ \\
\hline Q2. Você já recebeu ou recebe insultos verbais de seus alunos? & $23,5 \%$ & $76,5 \%$ \\
\hline $\begin{array}{l}\text { Q3. Você já teve seus pertences, furtado ou danificado e desconfia que sejam seus } \\
\text { alunos? }\end{array}$ & $27,5 \%$ & $72,5 \%$ \\
\hline Q4. Você já foi intimidado por algum aluno que portava arma de fogo ou branca? & $7,8 \%$ & $92,2 \%$ \\
\hline $\begin{array}{l}\text { Q5. Você já vivenciou ou vive alguma situação de extorsão, tendo que favorecer } \\
\text { contra sua vontade alguns de seus alunos à passar de ano ou favorecer seu } \\
\text { desempenho? }\end{array}$ & $6,9 \%$ & $93,1 \%$ \\
\hline $\begin{array}{l}\text { Q6. Você teme ou temeu por sua integridade física ao repreender por qualquer motivo } \\
\text { algum aluno? }\end{array}$ & $39,6 \%$ & $60,4 \%$ \\
\hline $\begin{array}{l}\text { Q7. Você teve receio de impedir uma situação de conflito entre os alunos por receio } \\
\text { de sofrer com represálias por partes dos mesmos em outras oportunidades? }\end{array}$ & $41,2 \%$ & $58,8 \%$ \\
\hline $\begin{array}{l}\text { Q8. Sentiu-se assediado(a) sexualmente por alunos(as) durante exercício da } \\
\text { profissão? }\end{array}$ & $30,4 \%$ & $69,6 \%$ \\
\hline $\begin{array}{l}\text { Q9. Existe algum espaço físico na escola onde você sente-se inseguro ou intimidado } \\
\text { no momento? }\end{array}$ & $12,7 \%$ & $87,3 \%$ \\
\hline $\begin{array}{l}\text { Q10. Sentiu-se ameaçado como ao ponto de pedir segurança policial para entrar ou } \\
\text { sair da escola? }\end{array}$ & $2 \%$ & $98 \%$ \\
\hline Q11. Você já tentou pedir ajuda a seus superiores? & $31,6 \%$ & $68,4 \%$ \\
\hline Q11.1 Se sim, o problema foi resolvido? & $40,8 \%$ & $59,2 \%$ \\
\hline
\end{tabular}

\section{Em relação ao tempo de Magistério}

Para realização desta análise, os participantes foram divididos em dois grupo: os professores até 10 anos de magistério obtendo um número de 50 professores e o restante acima de 10 anos de magistério obtendo um número de 52 professores. Buscou-se verificar a existência de associação entre as respostas do questionário em relação ao tempo de magistério. Através do teste do Qui-quadrado adotando um $p<0,05$ não foi encontrada diferenças significativamente estatística nesta comparação, constatando assim não haver associação entre as questões relacionadas à violência na relação entre professores e alunos do ponto de vista da diferença do tempo de atuação profissional.

\section{Em relação à carga horária semanal}

Para realização desta análise, os participantes foram divididos em três grupos distribuídos por frequência de classe: os professores com carga horária semanal entre $15-29$; 30-44; 45-60 horas semanais. Buscou-se verificar a existência de associação entre as respostas do questionário em relação à carga horária semanal. Através do teste do Qui-quadrado adotando um $p<0,05$ não foi encontrada estatisticamente diferenças significativa, constatando assim não haver associação entre as questões relacionadas à violência na relação entre professores e alunos do ponto de vista da diferença entre a carga horária semanal.

\section{Em relação ao estado civil}

Para realização desta análise, os participantes foram divididos em dois grupos: os professores "solteiros" obtendo um número de 35 professores e "casados" com número de 60 professores, buscando verificar a existência de associação entre as respostas do questionário em relação ao estado civil. Através do teste do Qui-quadrado adotando um $p<0,05$ foi encontrada diferença significativamente estatística. $O$ valor da diferença foi $\left(X^{2}=3,906 ; p=0,048\right)$ na questão "você já vivenciou ou vive algum episódio referente à "atos de violência" no ambiente escolar?". Esta associação indicou que os professores "solteiros" possuem uma menor exposição a este tipo de problema em relação aos professores "casados". 
Embora os professores solteiros possuam menor exposição a este problema, pode-se perceber utilizando o teste $U$ de Mann- Whitney, que em relação ao tempo de vivência destas situações, ou medo de vivenciá-las durante $o$ ano letivo, os professores solteiros quando vitimizados, possuem maior tempo de exposição a este problema ao longo da carreia docente $(U=432,5$; $p=0,018)$.

\section{Em relação ao número de escolas}

Para realização desta análise, os participantes foram divididos em dois grupos: os professores que ministram aula em apenas 1 estabelecimento de ensino, obtendo um número de 34 professores, e os professores que ministram aula em mais de 1 estabelecimento de ensino com número de 68 professores. Buscando verificar a existência de associação entre as respostas do questionário em relação ao número de escolas, utilizou-se o teste do Qui-quadrado adotando um $p<0,05$ onde foi encontrada diferença na associação. $O$ valor da diferença foi $\left(X^{2}=4,365\right.$; $\mathrm{p}=0,037)$ na questão "existe algum espaço físico na escola onde você sente-se inseguro ou intimidado no momento?". Esta associação indicou que os professores que ministram aula em apenas "um estabelecimento de ensino" sentem-se mais seguros em seu local de trabalho.

\section{Em relação ao sexo}

Para realização desta análise, os participantes foram divididos em dois grupos: os professores do sexo masculino e feminino totalizando um número de 51 professores para cada grupo. Através do teste do Qui-quadrado adotando um $p<0,05$ foram encontradas diferenças estatísticas significativamente nesta comparação na questão "você já tentou pedir ajuda a seus superiores?". 0 valor da diferença foi $\left(X^{2}=9,028 ; p=0,003\right)$ indicando que os professores do sexo feminino solicitam mais a ajuda de terceiros para solucionar os problemas no local de trabalho.

Outro resultado interessante foi em relação à questão "você teve receio de impedir uma situação de conflito entre os alunos por receio de sofrer com represálias por partes dos mesmos em outras oportunidades?". O percentual de resposta tanto para homens como para mulheres foi idêntico. Cerca de $58,8 \%$ e $41,2 \%$ responderam "não" e "sim" respectivamente.

\section{Em relação à divisão de cidades por região}

A tabela 3 corresponde aos valores em percentuais das frequências de respostas e do teste do Qui-quadrado adotando um $\mathrm{p}<0,05$ correspondente as questões do questionário sobre comportamentos de violência na relação professor-aluno comparados entre as "regiões" descritas na metodologia.

Através desta análise constatou-se que os professores que ministram aula na "região 1" de forma geral, sofrem mais com problemas relativos a violência escolar oriunda por seus alunos, em relação aos professores da "região 2". Esta diferença significativamente estatística foi verificada nas questões (Q1, Q2, Q7e Q11).

Em relação à pergunta "você já recebeu ou recebe insultos verbais de seus alunos?", do total dos participantes que afirmaram esta indagação (76,5\%), 45 são professores da "região 1" e 30 professores fazem parte da "região 2". A figura 2, representa a associação obtida com o teste Quiquadrado $\left(X^{2}=16,216 ; \quad p=0,006\right)$ entre a frequência semanal destas ações diante as respostas dos professores divididos pelas regiões. Embora a maior frequência $(60,0 \%)$ seja em relação aos professores da "região 2", estes vivenciam estas ações apenas uma " 1 dia da semana". A preocupação encontra-se em relação aos docentes da "região 1 ", devido a frequência semanal $(53,3 \%)$ destas ações se perpetuarem durante toda jornada de trabalho.

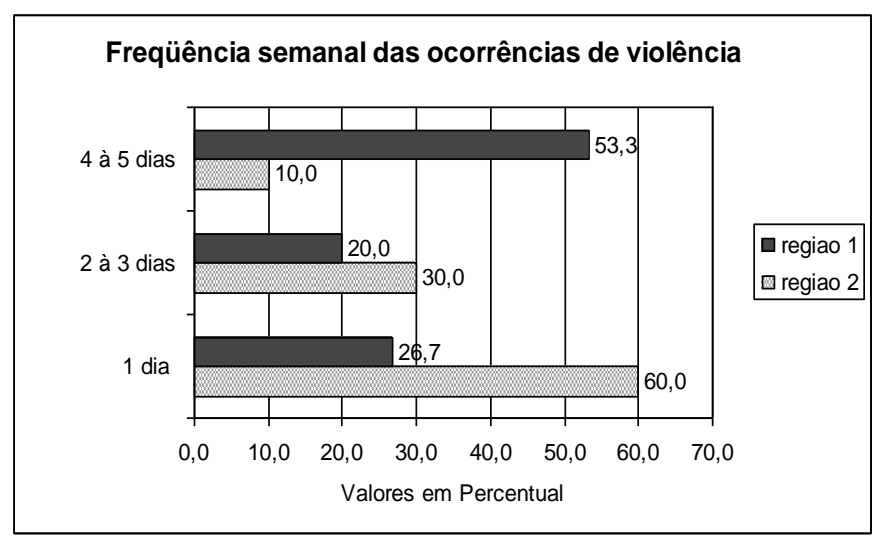

Figura 2. Frequência semanal das ocorrências de violência 
Tabela 3. Associação entre as regiões do estado em relação ao questionário

\begin{tabular}{|c|c|c|c|c|c|}
\hline & & $\begin{array}{l}\text { Região } 1 \\
n=55\end{array}$ & $\begin{array}{c}\text { Região } 2 \\
n=47\end{array}$ & $x^{2}$ & p \\
\hline \multirow{2}{*}{$\begin{array}{l}\text { Q1. Você já vivenciou ou vive algum episódio referente à } \\
\text { "atos de violência" no ambiente escolar? }\end{array}$} & não & $5,5 \%$ & $21,3 \%$ & \multirow{2}{*}{5,649} & \multirow{2}{*}{0,017 * } \\
\hline & $\operatorname{sim}$ & $94,5 \%$ & $78,7 \%$ & & \\
\hline \multirow{2}{*}{$\begin{array}{l}\text { Q2. Você já recebeu ou recebe insultos verbais de seus } \\
\text { alunos? }\end{array}$} & não & $12,7 \%$ & $36,2 \%$ & \multirow[t]{2}{*}{7,665} & \multirow[t]{2}{*}{0,006 * } \\
\hline & $\operatorname{sim}$ & $87,3 \%$ & $63,8 \%$ & & \\
\hline \multirow{2}{*}{$\begin{array}{l}\text { Q3. Você já teve seus pertences, furtado ou danificado e } \\
\text { desconfia que sejam seus alunos? }\end{array}$} & não & $70,9 \%$ & $74,5 \%$ & \multirow[t]{2}{*}{0,160} & \multirow[t]{2}{*}{0,690} \\
\hline & $\operatorname{sim}$ & $29,1 \%$ & $25,5 \%$ & & \\
\hline \multirow{2}{*}{$\begin{array}{l}\text { Q4. Você já foi intimidado por algum aluno que portava } \\
\text { arma de fogo ou branca? }\end{array}$} & não & $92,7 \%$ & $91,5 \%$ & \multirow[t]{2}{*}{0,053} & \multirow[t]{2}{*}{0,818} \\
\hline & $\operatorname{sim}$ & $7,3 \%$ & $8,5 \%$ & & \\
\hline \multirow{2}{*}{$\begin{array}{l}\text { Q5. Você já vivenciou ou vive alguma situação de extorsão, } \\
\text { tendo que favorecer contra sua vontade alguns de seus } \\
\text { alunos à passar de ano ou favorecer seu desempenho? }\end{array}$} & não & $96,4 \%$ & $89,4 \%$ & \multirow[t]{2}{*}{1,925} & \multirow[t]{2}{*}{0,165} \\
\hline & sim & $3,6 \%$ & $10,6 \%$ & & \\
\hline \multirow{2}{*}{$\begin{array}{l}\text { Q6. Você teme ou temeu por sua integridade física ao } \\
\text { repreender por qualquer motivo algum aluno? }\end{array}$} & não & $37,0 \%$ & $42,6 \%$ & \multirow[t]{2}{*}{0,317} & \multirow[t]{2}{*}{0,574} \\
\hline & $\operatorname{sim}$ & $66,0 \%$ & $57,4 \%$ & & \\
\hline \multirow{2}{*}{$\begin{array}{l}\text { Q7. Você teve receio de impedir uma situação de conflito } \\
\text { entre os alunos por receio de sofrer com represálias por } \\
\text { partes dos mesmos em outras oportunidades? }\end{array}$} & não & $43,6 \%$ & $76,6 \%$ & \multirow[t]{2}{*}{11,255} & \multirow[t]{2}{*}{0,001 * } \\
\hline & $\operatorname{sim}$ & $56,4 \%$ & $23,4 \%$ & & \\
\hline \multirow{2}{*}{$\begin{array}{l}\text { Q8. Sentiu-se assediado(a) sexualmente por alunos(as) } \\
\text { durante exercício da profissão? }\end{array}$} & não & $74,5 \%$ & $63,8 \%$ & \multirow[t]{2}{*}{1,362} & \multirow[t]{2}{*}{0,243} \\
\hline & sim & $25,5 \%$ & $36,2 \%$ & & \\
\hline \multirow{2}{*}{$\begin{array}{l}\text { Q9. Existe algum espaço físico na escola onde você sente- } \\
\text { se inseguro ou intimidado no momento? }\end{array}$} & não & $83,6 \%$ & $91,5 \%$ & \multirow[t]{2}{*}{1,392} & \multirow[t]{2}{*}{0,238} \\
\hline & sim & $16,4 \%$ & $8,5 \%$ & & \\
\hline \multirow{2}{*}{$\begin{array}{l}\text { Q10. Sentiu-se ameaçado com ao ponto de pedir segurança } \\
\text { policial para entrar ou sair da escola? }\end{array}$} & não & $96,4 \%$ & $100 \%$ & \multirow[t]{2}{*}{1,726} & \multirow[t]{2}{*}{0,189} \\
\hline & sim & $3,6 \%$ & $0 \%$ & & \\
\hline \multirow{2}{*}{ Q11. Você já tentou pedir ajuda a seus superiores? } & não & $18,0 \%$ & $46,7 \%$ & \multirow[t]{2}{*}{8,913} & \multirow[t]{2}{*}{0,003 * } \\
\hline & $\operatorname{sim}$ & $82,0 \%$ & $53,3 \%$ & & \\
\hline \multirow{2}{*}{ Q11.1 Se sim, o problema foi resolvido? } & não & $39,5 \%$ & $42,4 \%$ & 0,064 & 0,801 \\
\hline & $\operatorname{sim}$ & $60,5 \%$ & $57,6 \%$ & & \\
\hline
\end{tabular}

Região 1-(Paranavaí, Loanda, Terra Rica, Nova Esperança, Alto Paraná, Tamboara, Itaguagé, Paranacity e Cruzeiro do Sul). Região 2- (Ponta Grossa, Castro, Piraí do Sul, São Mateus do Sul e São João do Triunfo).

\section{Discussão}

De acordo com Waiselfisz (2004) a partir dos apontamentos de idealizados por Debarbieux deve-se considerar a violência e insegurança no meio escolar a partir de três hipóteses, uma como os crimes de delitos tais quais furtos, roubos, assaltos, consumo de drogas; a segunda como as incivilidades, que posteriormente remetem a terceira com um sentimento de insegurança. Assim Santini e Neto, 2005 constataram que os fatores sociais como violência, medo e insegurança aparecem de modo significativo dentro do processo de desgaste e esgotamento emocional nos professores. Os nossos resultados mostraram que esta hipótese pode ser confirmada, pois os altos índices $(87,3 \%)$ destas situações cotidianas confirmam a exposição a atos de violência sofrida pelos docentes.

Para Abramovay (2005a) os xingamentos entre alunos são uma espécie de demarcam territorial na relação "entre pares ${ }^{1 "}$. Segundo Levandoski (2009) existem ações como gozação e zoação na visão êmica, que não caracterizam um abuso entre poder, os próprios alunos afirmam que algumas destas atividades são realizadas apenas para sair de uma rotina em sala de aula. Contudo Abramovay (2005a) complementa que estas ações são agressões verbais quando envolvem os adultos, pois permeia assim uma marca de desrespeito e do questionamento da autoridade. A indiferença à presença do professor e a desconsideração ao poder dos docentes na escola são pontos de tensão no relacionamento entre alunos $e$ professores. Neste estudo percebeu-se que $76,5 \%$ afirmam a ocorrência deste fato, porém na visão ético o problema é saber se estas ações intrinsecamente aos alunos foram atos 
intencionalmente desrespeitosos ou apenas uma brincadeira rotineira resultando numa diminuição do status do professor.

Nota-se que o sentimento de medo torna-se presente no ambiente de trabalho. Segundo Abramovay e Avancini (2003) quando os professores são questionados sobre a presença de armas de fogo, as respostas positivas variaram de $2 \%$ a $8 \%$, e quando mencionam a presença de armas brancas os valores aumentam entre $8 \% \mathrm{e}$ $19 \%$ em escolas de quatorze estados brasileiros. Corroborando, percebeu-se que $7,8 \%$ dos docentes avaliados já foram intimidados com arma de fogo ou branca. Em consequência disto Abramovay (2005a) relata que os professores também são vítimas de roubos, perfazem um total de $8 \%$ em grupo de quase dois mil pesquisados que já tiveram seus pertences roubados ou danificados. Em nosso estudo a porcentagem deste tipo de ocorrência foi três vezes maior.

De acordo com Abramovay e Rua (2002) algumas pesquisas norte-americanas advogam que $o$ porte de armas significa para os jovens, mais do que a intenção em perpetrar algum crime, proteger-se e defender-se. Para Waiselfisz (2004) é na idade entre 15 e 24 anos que se encontram os maiores índices de homicídios no Brasil, desta forma a preocupação torna-se relevante, pois é nesta faixa etária em que estão presente a maior parcela da população estudantil. Outro fato apontado por Abramovay (2005a) são de que existem inúmeros relatos de professores que sofrem ameaças através de arma de fogo e branca por alunos, fato também comprovado em nossa pesquisa. Segundo Abramovay e Rua (2002) as principais causas das ameaças feitas por alunos aos professores, são devido a reprovações oriundas do fraco desempenho estudantil.

A partir de nossos resultados, percebeu-se que $30,4 \%$ do total de professores já foram assediados em seu local de trabalho. Para Abramovay e Rua (2002) o assédio sexual é percebido como uma das formas mais comuns de violência. Tanto professores e alunos, estão sujeitos a serem vítimas ou autores desta prática. Dividindo os participantes por sexo, observou-se que $35 \%$ e $25 \%$ dos professores do sexo

\footnotetext{
1 PEREIRA, Beatriz Oliveira. Para uma escola sem violência: estudo e prevenção das práticas agressivas entre crianças. Lisboa: Fundação Calouste Gulbenkian, 2002.
}

masculino e feminino respectivamente, já foram vítimas de assédio sexual pelos alunos.

$\mathrm{Na}$ concepção de diretores, professores e funcionários a policia só é necessária quando ocorre algum delito ou crime. A tendência a definir violência como um episódio desta ordem justificaria a ação da polícia (ABRAMOVAY, 2005a). Neste estudo verificou-se que $2 \%$ dos participantes já se sentiram ameaçados a ponto de pedir segurança policial para entrar ou sair da escola.

Assim Abramovay (2005a), discute que a escola nem sempre se mostra capaz de resolver o conflito de maneira mais adequada, uma vez que uma postura assumida pelas autoridades da escola parece ser a de minimizar ou desconsiderar a importância do ocorrido. Neste estudo, segundo os $68,4 \%$ dos professores pesquisados afirmaram terem procurado ajuda dos seus superiores. Deste percentual $40,8 \%$ não tiveram o problema solucionado causando uma situação de desconforto para o professor. A sensação de impunidade, faz com que a qualquer momento estas situações acabem se repetindo já que o agressor não tem nenhum tipo de punição por seu ato.

Em resumo as análises estatísticas foram realizadas a partir de sete variáveis independentes, associando os aspectos relativos à violência oriunda por discentes na relação com os discentes. Percebeu-se que tanto em relação à idade, tempo de magistério e carga horária semanal dos professores participantes, não foram encontradas evidencias estatísticas na associação com aspectos da violência no ambiente escolar. Diferentemente, as variáveis, estado civil, número de escolas de atuação, distinção por sexo e divisão das cidades pela região geográfica que, apresentaram evidencias para associar este problema de estudo com a opinião dos docentes.

\section{Conclusão}

Em suma, o presente estudo verificou a existência de atos de violência contra professores de educação física na rede de ensino público de algumas cidades do estado do Paraná. É importante ressaltar que independentemente das variáveis estatisticamente analisadas, percebeuse que a violência contra os docentes nesta relação professor-aluno encontra-se em um nível grave. 
Verificou-se que os professores da região noroeste do estado, estão mais expostos a situações de agressão pelos alunos em relação aos professores da região central. Esta mesma relação aconteceu aos professores solteiros comparados aos professores casados analisando o total de participantes. Destacamos que os professores que ministram aula em apenas um estabelecimento de ensino sentem-se mais seguros em seu local de trabalho e que os professores do sexo feminino solicitam mais a ajuda para solucionar os conflitos no local de trabalho.

Os profissionais estão sujeitos a esta exposição no ambiente escolar devido a vulnerabilidade do comportamento discente. De acordo com os participantes os alunos estão dispostos a resolver seus problemas utilizando estas ações de violência, a partir do ponto onde acreditem que em sua auto-percepção, tenham sido prejudicados.

Empiricamente pode-se descrever que os profissionais da educação em alguns casos também são vítimas do sistema político pedagógico. Porque em sua formação embora adquiram conhecimento sobre aspectos de indisciplina no meio escolar, não são preparados para atuar com estas situações adversas ao ementário curricular. Outrora vimos, o surgimento de legislações que protegem estes profissionais diante as situações de violência dos alunos, como à cartilha "Normas Gerais de Conduta Escolar" no publicada no ano de 2009 no estado de São Paulo.

Em estudos futuros a preocupação consiste em explorar através de uma abordagem qualitativa as informações quantitativas obtidas neste estudo, bem como comparar estes resultados com os professores de outras disciplinas.

\section{Referências}

ABRAMOVAY, M. Violencias en las escuelas: un gran desafio. Revista Iberoamericana de Educación, Espanha, v.38, p.55-66, 2006.

ABRAMOVAY. M. (Coord). Cotidiano das escolas: entre violências. Brasília: UNESCO, 2005a.

ABRAMOVAY, M. Victimización en las escuelas: ambiente escolar, robos y agresiones físicas.

Revista Mexicana de Investigación Educativa, Tlalpan, v.10, núm. 26, pp. 833-864, 2005b.
ABRAMOVAY, M.; AVANCINI, M. M. P. A violência e a escola: o caso Brasil. In: CONFERÊNCIA INTERNACIONAL DE VIOLÊNCIA NA ESCOLA, 2, 2003, Québec. Anais.... Québec: [S.n.], 2003.

ABRAMOVAY, M.; RUA, M. G. Violências nas escolas. 2. ed. Brasília: UNESCO, 2002.

BLAYA, C.; BAUDRIT, A. ¿Entre necesidad y factibilidad?: el mentorado de profesores al principio de su carrera para el manejo de situaciones difícile. Revista Mexicana de Investigación Educativa, Tlalpan, v.10, n.26, p. 765-786, 2005.

CORREIA, R. N. P. Competência do professor de educação física: um estudo com professores da rede pública. 2008. Dissertação (Mestrado em Educação Física) - Universidade de São Paulo, São Paulo, 2008.

DEBARBIEUX, E. (Org). Violência nas escolas e políticas públicas. Brasília: UNESCO, 2002.

DESLANDES, S. F. Atenção a crianças e adolescentes vítimas de violência doméstica: análise de um serviço. Cadernos de Saúde Pública, Rio de Janeiro, v.10, supl.1, p.177-187, 1994.

DORREY, R. C. C. Los maestros frente a la violencia entre alumnos. Revista Mexicana de Investigación Educativa, Tlalpan, v.10, n.27, p. 1071-1082, 2005.

FERNANDEZ, C. M.; AGUADO, I. H.; CANTERO, A. M. T.. Percepción de la violencia escolar por parte de las personas responsables de la dirección de los centros de enseñanza de Alicante: un estudio cualitativo. Revista Espanola de Salud Publica, v.80, n.4, p. 387-394, 2006.

GASPARINI, S. M.; BARRETO, S. M.; ASSUNÇÃO, A. Á. Prevalência de transtornos mentais comuns em professores da rede municipal de Belo Horizonte, Minas Gerais, Brasil. Cadernos de Saúde Pública, Rio de Janeiro, v.22, n.12, p.2679-2691, dez. 2006.

GLINA. D. M. R; GARDIN. A. de C. Assédio moral no trabalho: aspectos conceituais, jurídicos e preventivos. Saúde, Ética \& Justiça, São Paulo, n.10, p.38-47, 2005.

GOMES, C. A.; PEREIRA, M. M. A formação do professor em face das violências das/nas escolas. Cadernos de Pesquisa, São Paulo, v.39, n.136, p.201-224, jan./abr. 2009.

LEVANDOSKI, G. Análise de fatores associados ao comportamento bullying no ambiente escolar: características 
cineantropométricas e psicossociais. 2009. Dissertação (Mestrado em Ciências do Movimento Humano) - Universidade do Estado de Santa Catarina, Florianópolis, 2009.

LOPES NETO, A. A. Bullying: comportamento agressivo entre estudantes. Jornal de Pediatria, Rio de Janeiro, v.81, n.5, p.64- 172, 2005.

MINAYO, M. C. de S. A violência social sob a perspectiva da saúde pública. Cadernos de Saúde Pública, Rio de Janeiro, v.10, n.1, p.0718, 1994.

\section{PEREIRA, B. O. Para uma escola sem} violência: estudo e prevenção das práticas agressivas entre crianças. Lisboa: Fundação Calouste Gulbenkian, 2002.

RICCI, R. O perfil do educador para o século XXI: de boi de coice a boi de cambão. Educação \& Sociedade, v.20, n.66, p.143-178, 1999.

RISTUM, M.; BASTOS, A. C. de S. Violência urbana: uma análise dos conceitos de professores do ensino fundamental. Ciência \& Saúde Coletiva, Rio de Janeiro, v.9, n.1, p.225-239, 2004.

SANTINI. J; NETO. M. V. A síndrome do esgotamento profissional em professores de educação física: um estudo na rede municipal de ensino de porto Alegre. Revista brasileira de Educação Física e Esporte, São Paulo, v.19, n.3, p.209-22, jul./set. 2005.

SEBASTIÃO. J; ALVES. M. G; CAMPOS. J. Violência na escola: das políticas aos quotidianos. Sociologia, Problemas e Práticas, Lisboa, n.41, p.37-62, 2003.

SPOSITO, M. P. Um breve balanço da pesquisa sobre violência escolar no Brasil. Educação e Pesquisa, São Paulo, v.27, n.1, p.87-103, jan./jun. 2001.

SPOSITO, M. P. A Instituição escolar e a violência. Cadernos de Pesquisa, São Paulo, v.104, p.58-75, 1998.

TOKUYOCHI, J. H. et. al. Retrato dos professores de educação física das escolas estaduais do estado de São Paulo. Motriz, Rio Claro, v.14, n.4, p.418-428, out./dez. 2008.

TROMBETTA. T. Características do assédio moral alunos- trabalhadores nos seus locais de trabalho. 2005. 135f. Dissertação (Mestrado em Psicologia) - Universidade Federal de Santa Catarina, Florianópolis, 2005. EDUCAÇÃO, CIÊNCIA E CULTURA (UNESCO).
Violência na escola: América Latina e Caribe. UNESCO, Brasília, 2003.

WAISELFISZ, J. J. Mapa da violência IV: os jovens do Brasil. Brasília: UNESCO, 2004.

WORLD HEALTH ORGANIZATION. World report on violence and health. Geneva: WHO; 2002.

Agradecimento: Agradecemos aos acadêmicos e professores Aline Z. Milhan, Danielle Borges, Fernando M. A. Fernandes, Jair M. de Oliveira, Karol Liizi D. Carneiro, Marcelo de Oliveira, Mayara T. Ântico, Suzana Ap. de Oliveira e Thiago K. dos Santos que auxiliaram no processo de coleta dos dados, bem como aos professores que resposnderam o questionário.

Comitê de ética: Universidade Federal do Paraná CEP/SD: 622.159.08.09v CAAE: 3184.0.000.09108

Apoio: Coordenação de Aperfeiçoamento de Pessoal de Nível Superior CAPES

\section{Endereço:}

Gustavo Levandoski

Universidade Federal do Paraná

R. Coração de Maria,92 BR116km95 Jd. Botânico

Curitiba PR Brasil

e-mail: glevandoski@gmail.com

Recebido em: 28 de março de 2010. Aceito em: 28 de abril de 2011.

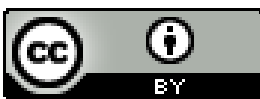

Motriz. Revista de Educação Física. UNESP, Rio Claro, SP, Brasil - elSSN: 1980-6574 - está licenciada sob Creative Commons - Atribuição 3.0 